\title{
Postgraduates' critical thinking practices while seeking for information
}

\author{
Mahboobeh Haghparast ${ }^{1}$, A. Noorhidawati ${ }^{2}$ and N. Fariza Hanum ${ }^{1}$ \\ ${ }^{1}$ Department of Information Systems \\ Faculty of Computer Science and Information Technology, \\ University of Malaya, Kuala Lumpur, MALAYSIA \\ ${ }^{2}$ Department of Library \& Information Science \\ Faculty of Computer Science and Information Technology, \\ University of Malaya, Kuala Lumpur, MALAYSIA \\ e-mail:m.haghparast@ieee.org; \\ noorhidawati@um.edu.my (corresponding author); fariza@um.edu.my;
}

\begin{abstract}
This paper reports on a small part of a larger research work on critical thinking practices among students when they seek for information. Critical thinking is a metacognitive process which an essential skill in education particularly in the 21st century. It is imperative when students need to find relevant and trustworthy information. The aims of this paper are twofold: i) to investigate the level of critical thinking among postgraduate students; ii) to investigate critical thinking practices among students when they seek for information. The study employed a quantitative research design. Watson-Glaser Critical Thinking Appraisal-UK (WGCTA-UK) edition was used to examine the level of critical thinking of postgraduate students. Another survey was conducted to investigate critical thinking practices of students during their information seeking process (ISP). Questionnaires were distributed on a random basis among postgraduate students in a pilot test. A total of 45 responses were gathered. The findings from the study revealed that postgraduate students had the highest score in "recognition of assumptions" and the lowest score in "inference" in the critical thinking practices. About 71 percent of the respondents scored below average and average in several areas of CT. The findings demonstrated when students seek for information, they use several CT skills (CTS) and CT dispositions (CTD) such as inference, recognition of assumption, deduction and evaluation of arguments.
\end{abstract}

Keywords: Critical thinking; Information seeking behavior; Information seeking process; Postgraduates

\section{INTRODUCTION}

In the 21st century, students must not only be highly knowledgeable, but must also be equipped with soft skills, which include critical thinking and problem-solving skills (Ledward and Hirata 2011). These skills will prepare them for post-secondary education, employment, and to become competent members of the society. The Common Core State Standards (Barrett et al. 2012) also mentioned that critical thinking (CT) is one of the vital cross-disciplinary skills for education and in the workplace (Lai 2011). Moreover, Dwyer, Hogan, and Stewart (2014) introduced CT as a metacognitive process. There are several definitions for CT depending on different viewpoints of researchers. Ennis (1991) defined CT as "reasonable, reflective thinking that is focused on deciding what to believe or do" 
(p.39). Lipman (1988) considered CT as skillful and responsible thinking that entails selfregulation and purposeful judgment. Facione (1990) described CT as "a purposeful and self-regulatory judgment which encompasses the interpretation, analysis, evaluation, and inference as well as explanations of different types of arguments based on logical judgment" (p.3). On the other hand, constant Internet coverage and several types of information are key factors to emerge the seeking appropriate information among users and researchers. Applying CT skills during information seeking is important because they provide the means for students to question assumptions, analyze arguments, and evaluate the quality of information inside and outside of their chosen fields (Bensley and Spero 2014).

Since CT has been a global issue, several researchers and individuals who concern about CT have conducted different studies. For instance, Bensley and Spero (2014) applied direct infusion as one of the instructional approaches to cultivate $\mathrm{CT}$. The findings revealed that infusion approach is effective in cultivating CT among participants. Problem-based learning as a teaching strategy has the potential to develop CT skills, therefore, it is used increasingly to develop CT skills among higher education students, including nursing students (Kek and Huijser 2011). Although, there are many studies about cultivating CT through instructional methods with emphasis on the information age and decision making about suitable information to solve a problem, there is no explicit evident literature about the effects of critical thinking of information seeking behavior (ISB). Meanwhile a claim made by (Behar-Horenstein and Niu 2011; Ennis 1989) stated that those who think critically are able to seek information that is not only of quality but is also accurate.

According to Wilson (1999) many information behavior models were rooted from library and information science (LIS) research. Information seeking process model (ISP) suggested by (Kuhlthau 1991) is relevant in this research context. This is because the model was developed for an information literacy program that relates the information seeking process of users in the learning and problem solving process when they are working on a research project. Kuhlthau (1991) asserted that users utilized various information resources to meet their needs but they may have difficulties in the early stages of information seeking, especially for those who were preparing for a research paper. Institutes of higher learning nowadays emphasize more on the importance of producing graduates with good quality in soft skills as such in CT skills, although they are in general are facing with the problem of lacking CT skills among the students. Hence, this paper reports on the level of critical thinking (CT) among postgraduate students and their CT practices when they seek for information.

\section{LITERATURE REVIEW}

\section{Critical thinking}

Ennis (1987) provided a taxonomy for CT which includes dispositions and skills such as clarify the problem; identify the problem; formulate a question; gather information; distinguish relevant from irrelevant information; make inference; deductive reasoning, recognize unwarranted claims; conduct advanced clarification; determine the strength of arguments; decide on answer, solution or course of action; and make a judgment. Several researches were conducted based on Ennis' (1987) CT taxonomy which demonstrated that CT can be taught (De Wever et al. 2006, Colucciello 1999, Webb 1994). ten Dam and Volman (2004) on the other hand have used the CT taxonomy to demonstrate that CT can Page | 36 
be understood and taught as a set of general cognitive skills and dispositions. Tsui (2002) in addition reported that there were several arguments on the connection between $\mathrm{CT}$ and problem solving. Although these studies focused on the CT taxonomy and also the relationship with several factors such as learning styles (Colucciello 1999), reading (Aloqaili 2012), writing (Naber and Wyatt 2014), thinking styles (Lun, Fischer, and Ward 2010), and classroom interaction (Yiqi 2012), there is no explicit evidence from the literature that report the importance of CT in ISP.

\section{Information seeking process}

Information seeking behavior is a process driven by humans' needs for information so that they can interact with the environment, emphasizing communication and the needs, characteristics, and actions of information seekers (Marchionini 1997). There are famous models for information seeking, such as behavioral model of ISB (Ellis and Haugan 1997), information seeking process (ISP) (Kuhlthau 1991), and problem-solving model (Wilson 1997). Prior research on ISB has focused on key factors that influenced on information seeking practices including, relationship between ISB in several disciplines, such as physics and astronomy (Jamali and Nicholas 2010), humanities (Madden 2014) and computer science (Liyana and Noorhidawati 2014). In addition the studies also reported on demographic connections such as education status and gender (Zhou 2014), respondent's position, based on their jobs and fields (Al Qadire 2014), information needs (Weiler 2005), personal traits (Malliari, Korobili, and Zapounidou 2011), and information literacy (Wahoush and Banfield 2014, Williamson and Asla 2009, Branch 2003). The literature revealed that information seeking behavior and process have been attractive subjects in various viewpoints. For example, emerging the information and communication technologies (ICT) changed the facets of information seeking behavior and process among different group of users. Therefore, scholars have been keen in tracing the information seeking behavior of different seekers such as scientists, doctoral students, undergraduate students, secondary students, and even individuals in their daily lives (Spezi 2016).

The ISP model (Kuhlthau 1991) includes six stages as discussed above. In the initiation stage, information seekers would recognize their needs for information to go to the second stage which is called selection. In selection, they identify and select the general topic to be investigated or the approach to be pursued. The third stage is an exploration that needs the information seekers to investigate information on the general topic in order to extend personal understanding. In formulation which is the fourth stage of ISP, the information seekers form a search focus from the information encountered to go to the next stage that is information collection, as they gather related information to the given topic. Finally, the information seekers complete the search and prepare to present or otherwise use the findings. Kuhlthau (1991) represented the user's sense-making process and incorporates three realms of human experience includes feelings, thoughts, and actions in each stages. Although her study was conducted in a traditional library environment, Kuhlthau's findings suggest that user cognitive, physical, and affective states are the driving force in any information seeking process.

Many LIS researches on ISB have been inspired by Kuhlthau's model. For instance, Poteri (2007) reported the differences between bachelor and doctoral students and researchers' information needs and seeking. His findings reported that researchers were preferred to ask colleagues instead of seeking help from the librarians. They were not interested towards information literacy training programs compared to bachelor and doctoral students. Hyldegård (2006) has also investigated how Kuhlthau's ISP-model was applied in the information behavior of group of people in an academic setting. She reported 
differences between individual and group information seeking behavior mainly related to contextual, social and personal factors. There were several studies on ISP and feelings such as studies conducted by (Chowdhury, Gibb, and Landoni 2011, Wilson et al. 2002) on ISP and uncertainty and ISP and anxiety (Erfanmanesh, Abrizah, and Karim 2014). Moreover, several researchers have studied the ISP from different views such as on tasks (Xie 2009), effects of information seeking process in collaborative task-based (Shah and GonzálezIbáñez 2010), and in virtual learning environment (Byron and Young 2000). In spite of these studies, there is little work reported on CT skills and dispositions in ISB to date.

\section{METHOD}

The main purpose of the paper is to investigate whether postgraduate students think critically while they seek information and which CT skills they use during the information seeking process. In order to address this purpose, the following research questions are postulated:

RQ1: What is the level of critical thinking of postgraduate students?

RQ2: How postgraduate students critically think when seeking for information?

This study employed a quantitative method using survey as the research design. Two sets of survey questionnaire were distributed among postgraduate students affiliated to research centers at a research-intensive university in Kuala Lumpur, Malaysia. A total of 45 responses were gathered that included Masters and Doctoral students in different disciplines such as Engineering, Education, Medicine, Computer Science, Science, Business, and Economics. The demographic details of respondents are presented in Table 1.

Table 1: Demographic details of respondents

\begin{tabular}{l|l||c|c}
\hline \hline \multicolumn{2}{l||}{ Characteristics $(\mathbf{n}=\mathbf{4 5})$} & Frequency & Percentage \\
\hline \hline \multirow{2}{*}{ Degree } & Bachelor & 11 & $24.4 \%$ \\
\cline { 2 - 4 } & Master & 34 & $75.6 \%$ \\
\hline \hline \multirow{2}{*}{ Field } & Computer science & 31 & $68.9 \%$ \\
\cline { 2 - 4 } & Education & 1 & $2.2 \%$ \\
\cline { 2 - 4 } & Engineering & 9 & $20.0 \%$ \\
\cline { 2 - 4 } & Medicine & 1 & $2.2 \%$ \\
\cline { 2 - 4 } & Science & 3 & $6.7 \%$ \\
\hline \hline \multirow{3}{*}{ Gender } & Male & 33 & $73.3 \%$ \\
\cline { 2 - 4 } & Female & 12 & $26.7 \%$ \\
\cline { 2 - 4 } & $20-25$ & 5 & $11.1 \%$ \\
\cline { 2 - 4 } & $26-30$ & 12 & $26.7 \%$ \\
\cline { 2 - 4 } & $31-35$ & 5 & $42.2 \%$ \\
\cline { 2 - 4 } & $36-40$ & 4 & $8.9 \%$ \\
\cline { 2 - 4 } & Over 41 & & \\
\hline \hline
\end{tabular}

In order to investigate the level of CT of postgraduate students (as in the first research questions), Watson-Glaser Critical Thinking Appraisal (WGCTA) UK edition (Watson and Glaser 2002) was used. WGCTA-UK edition is known as a reliable and valid assessment tool (Hassan and Madhum 2007, Silvester and Dykes 2007). The questionnaire includes two 
sections; the first section is used to gather information on demographic characteristics and the second section consists of five parts based on five critical thinking skills - inference, recognition of assumptions, deduction, interpretation, and evaluation of arguments - with separate scenarios.

In order to address the second research question, another survey questionnaire was prepared to investigate postgraduate students' CT skill while they seek for information. The instrument was devised based on ISP model (Kuhlthau 1991) and the CT taxonomy (Ennis 1987). The ISP model (Kuhlthau 2004, 1991) includes five stages process of ISP. Common patterns of thinking, feeling and acting are found in each stage of the ISP model: initiation, selection/exploration, formulation, information collection, and presentation. While the CT skills involves 10 skills including: clarifying a problem, identify or formulate the question, gather information, distinguish relevant from irrelevant information, make an inference, deductive reasoning and recognize unwarranted claims; conduct advanced clarification, determines the strength of arguments, decides on answer, solution or course of action, and makes a judgment. This questionnaire was divided into 5 sections which comprise 5 stages of ISP that finally includes 50 items. In each stage of the ISP model, the usage of CT skills were rated in 5 points Likert scale (1=never, $2=$ sometimes, $3=$ usually, $4=$ often and 5 =always). Figure 1 is the preliminary model to show the relationship between CT skills in five stages of the ISP.

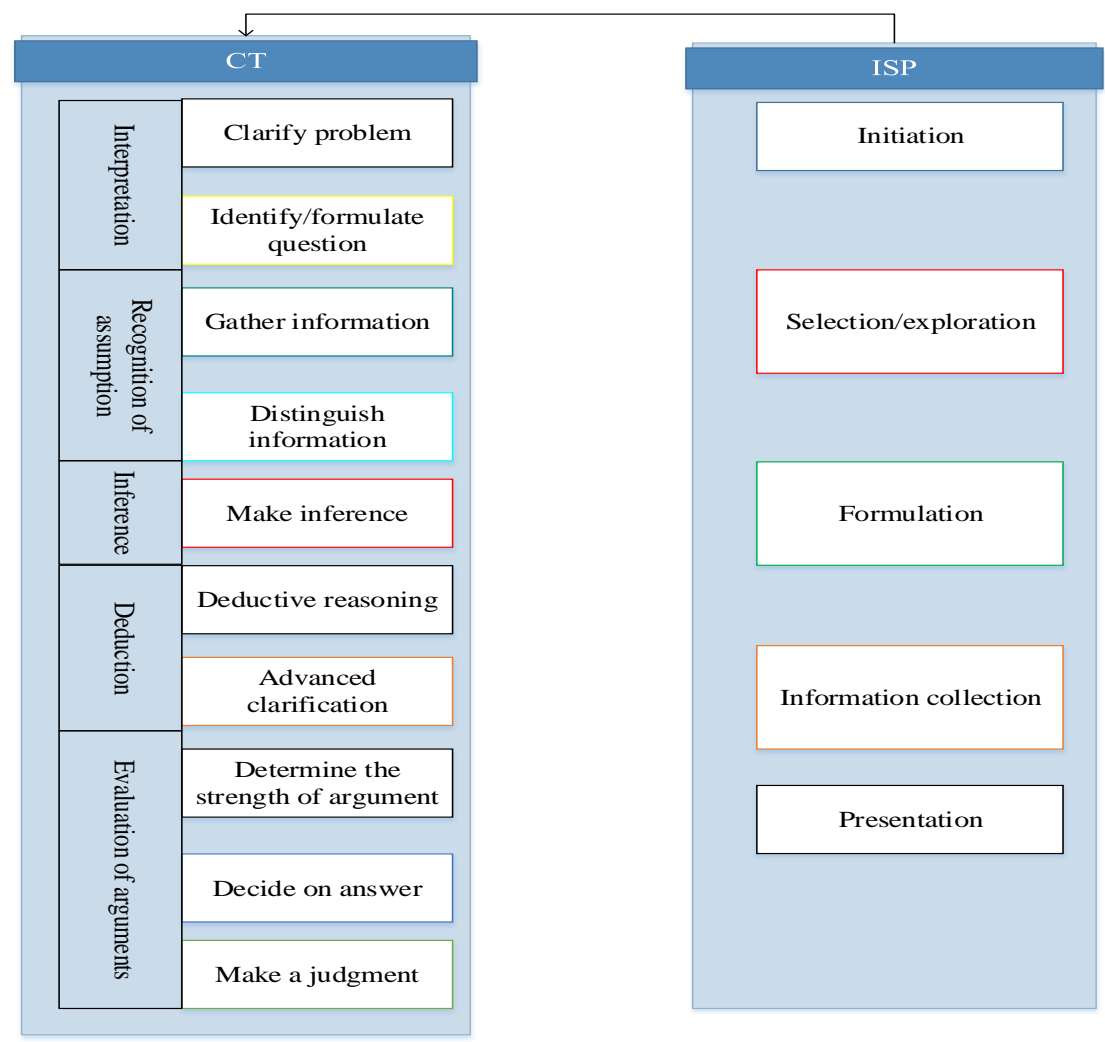

Figure 1: Model of Critical Thinking and Information Search Process

In the process of data analysis, the median and Inter-Quartile Range (IQR) value of each statement is worthy to pay attention to and included all responses to each statement. The median is used to measure the central tendency to reflect the "likeliest" response. The IQR is a measure of dispersion to show whether the responses are clustered together or 
scattered across the range of responses. Since the questionnaire adopts the method of 5 degrees Likert scale, the values from 1 to 5 to the options from "never" to "always", were assigned.

\section{Pilot Study}

Pilot study was conducted to assess the adequacy of survey instruments. The survey questionnaires were administrated to a number of students in one research group for the pilot test.. Feedbacks from the pilot study highlighted participants' comments related to unclear and difficult questions in the survey items. As a result, the questions were rephrased to use more simple terms and phrases.

Instrument Validity and Reliability Evaluation Content validity is an attempt to judge the degree of the consistency among the items in the questionnaire in terms of the content, skills, or objectives (Popham 2000). The WGCTA is a standard test for measuring CT skills with high validity and reliability as reported by Abrami et al. (2008). Therefore, the reliability and validity of WGCTA survey was proven. The second survey questionnaire however were developed based on the constructs taken from the CT taxonomy (Ennis 1987) and the ISP model (Kuhlthau 1991). The content validity of the survey was evaluated using face validation approach. Five experts' opinions from information seeking and critical thinking studies were sought to review the survey questionnaires. In general, the experts were in the opinion that the content of the questionnaires were sufficient and appropriate to answer the research objectives. In addition, construct validity of the survey questionnaires were evaluated using factor analysis test. For the factor analysis to be considered appropriate, Bartlett's test of Sphericity should be significant at $p<.05$, and values of the Kaiser-Meyer-Olkin (KMO) measure of sampling adequacy should be between 0.6 and 1.0 as shown in Table 2. For this study, scale items that recorded factor loading of less than 0.4 were not accepted (as shown in Table 3).

Table 2: Bartlett's Test and KMO Measure

\begin{tabular}{l||c||c||c}
\hline \hline Constructs of ISP & KMO & Bartlett's test Sig. & $\begin{array}{c}\text { Percentage of } \\
\text { Variance }\end{array}$ \\
\hline \hline Initiation & 0.688 & 0.000 & 32.909 \\
\hline \hline Selection/exploration & 0.739 & 0.000 & 35.472 \\
\hline \hline Formulation & 0.687 & 0.000 & 37.198 \\
\hline \hline Information collection & 0.656 & 0.000 & 39.372 \\
\hline \hline Presentation & 0.796 & 0.000 & 45.711 \\
\hline \hline
\end{tabular}

In order to assess the reliability of the survey questionnaires, the internal consistency of each scale was measured using Cronbach's alpha. Measures of reliability range from 0 to 1 , and each scale should exhibit adequate reliability with Cronbach's alpha close to or above the recommended 0.7 level as shown in Table 3. Table 4 shows the Median and Inter Quartile Ranking (IQR) for the research constructs analyzed in this paper. 
Table 3: Cronbach's Alpha and Factor Loading

\begin{tabular}{|c|c|}
\hline Initiation: Cronbach's $\alpha=0.747$ & Factor Loading \\
\hline 1. I clarify and interpret the meaning of the topic. & .625 \\
\hline 2. I can determine the existing information are related to the topic or not & 7.708 \\
\hline 3. I gather information & (2936 \\
\hline $\begin{array}{ll}\text { 4. I distinguish relevant information from irrelevant information about the topic. } \\
\text {. }\end{array}$ & .541 \\
\hline 5. I assess the information about the topic and identify to reach a reasonable conclusion. & .769 \\
\hline 6. I recognize the unwarranted information about the topic. & .662 \\
\hline 7. I define terms and judge definitions by using appropriate criteria. & .713 \\
\hline 8. I determine the strength of arguments or information about the topic. & .652 \\
\hline 9. I decide to find the suitable answer & .656 \\
\hline 10. I make a judgment about the answer and draw a conclusion & .536 \\
\hline Selection/exploration: Cronbach's $\alpha=0.740$ & Factor Loading \\
\hline 11. I clarify and interpret the meaning of the topic. & .555 \\
\hline 12. I can determine the existing information are related to the topic or not & .499 \\
\hline 13. I gather information & .723 \\
\hline 14. I distinguish relevant information from irrelevant information about the topic. & (2626 \\
\hline 15. I assess the information about the topic and identify to reach a reasonable conclusion. & .575 \\
\hline 16. I recognize the unwarranted information about the topic. & .764 \\
\hline 17. I define terms and judge definitions by using appropriate criteria. & .795 \\
\hline 18. I determine the strength of arguments or information about the topic. & .704 \\
\hline 19. I decide to find the suitable answer & .791 \\
\hline 20. I make a judgment about the answer and draw a conclusion & .786 \\
\hline Formulation: Cronbach's $\alpha=0.790$ & Factor Loading \\
\hline 21. I clarify and interpret the meaning of the topic. & .925 \\
\hline 22. I can determine the existing information are related to the topic or not & .722 \\
\hline 23. I gather information & .712 \\
\hline 24. I distinguish relevant information from irrelevant information about the topic. & .727 \\
\hline 25. I assess the information about the topic and identify to reach a reasonable conclusion. & .628 \\
\hline 26. I recognize the unwarranted information about the topic. & .847 \\
\hline 27. I define terms and judge definitions by using appropriate criteria. & .798 \\
\hline 28. I determine the strength of arguments or information about the topic. & .493 \\
\hline 29. I decide to find the suitable answer & .763 \\
\hline 30. I make a judgment about the answer and draw a conclusion & .886 \\
\hline Information collection: Cronbach's $\alpha=0.822$ & Factor Loading \\
\hline 31. I clarify and interpret the meaning of the topic. & - \\
\hline 32. I can determine the existing information are related to the topic or not & .628 \\
\hline 33. I gather information & .649 \\
\hline 34. I distinguish relevant information from irrelevant information about the topic. & .770 \\
\hline 35. I assess the information about the topic and identify to reach a reasonable conclusion. & .626 \\
\hline 36. I recognize the unwarranted information about the topic. & .736 \\
\hline 37. I define terms and judge definitions by using appropriate criteria. & .709 \\
\hline 38. I determine the strength of arguments or information about the topic. & .720 \\
\hline 39. I decide to find the suitable answer & .430 \\
\hline 40. I make a judgment about the answer and draw a conclusion & .752 \\
\hline Presentation: Cronbach's $\alpha=0.861$ & Factor Loading \\
\hline 41. I clarify and interpret the meaning of the topic. & .633 \\
\hline 42. I can determine the existing information are related to the topic or not & .732 \\
\hline 43. I gather information & .803 \\
\hline 44. I distinguish relevant information from irrelevant information about the topic. & .890 \\
\hline 45. I assess the information about the topic and identify to reach a reasonable conclusion. & .866 \\
\hline 46. I recognize the unwarranted information about the topic. & .820 \\
\hline 47. I define terms and judge definitions by using appropriate criteria. & .747 \\
\hline 48. I determine the strength of arguments or information about the topic. & .641 \\
\hline 49. I decide to find the suitable answer & .794 \\
\hline 50. I make a judgment about the answer and draw a conclusion & 871 \\
\hline
\end{tabular}

Note: The Scale Used: 1=Never; 2=Sometimes; 3=Usually; 4= Often; 5= Always 
Table 4: Median of the CT and ISP Constructs

\begin{tabular}{l||c|c}
\hline \multicolumn{1}{c||}{ Constructs } & \multicolumn{2}{c}{ Values } \\
\hline \hline Critical Thinking (CT) & 1.00 & 1.50 \\
\hline \hline Inference & 2.00 & 1.00 \\
\hline \hline Recognition of assumption & 2.00 & 1.00 \\
\hline \hline Deduction & 2.00 & 2.00 \\
\hline \hline Interpretation & 2.00 & 1.00 \\
\hline \hline Evaluation of arguments & & \\
\hline \hline Information Seeking Process (ISP) & 2.10 & 0.90 \\
\hline \hline Initiation & 2.20 & 1.10 \\
\hline \hline Selection/exploration & 2.20 & 1.33 \\
\hline \hline Formulation & 2.20 & 1.25 \\
\hline \hline Information collection & 2.30 & 1.70 \\
\hline \hline Presentation
\end{tabular}

Notes: The scales used for CT constructs are based on the WGCTA survey instrument where each construct has different scale including:

- Inference: $1=F a l s e ; 2=$ True

- Recognition of assumptions: $1=\mathrm{No} ; 2=\mathrm{Yes}$

- Deduction: $1=\mathrm{No} ; 2=\mathrm{Yes}$

- Interpretation: $1=$ No; $2=Y e s$

- Evaluation of arguments: $1=$ Weak; $2=$ Strong

Scales for ISP includes: 1=Never; 2=Sometimes; 3=Usually; 4= Often; 5= Always

\section{FINDINGS}

\section{Critical Thinking Level of Postgraduate Students}

The finding indicates a total score of 17 for the CT level. Among the 45 respondents who answered the survey, the range of CT skill level was from 5 to 14, with Mean=9.37, and Standard Deviation=2.083. Accordingly, $9(20 \%)$ respondents are below the average of CT skill level and $23(51 \%)$ respondents are in the average level, while only $13(29 \%)$ are above the average. Therefore, the findings indicate that more than 70 percent of respondents show lack of CT skill (Table 5).

Table 5: CT Skill Level of Respondents ( $n=45)$

\begin{tabular}{c||c||c}
\hline \hline Below average 0\%-40\% & Average 40\%-60\% & Above average $\mathbf{6 0 \% - 1 0 0 \%}$ \\
\hline \hline 9 & 23 & 13 \\
\hline \hline $20.00 \%$ & $51.11 \%$ & $28.88 \%$ \\
\hline \hline
\end{tabular}

According to the data range for each construct, the number of postgraduates who answered "false" to the questions related to the inference section ( $M d n=1.00, I Q R=1.50)$ is more than the other constructs in the CT skill. For example, "recognition of assumptions" was demonstrated as the strong CT skill among participants due to the number of "Yes" answer for the related questions $(M d n=2.00, I Q R=1.00)$. Table 6 illustrates the Median and IQR of all constructs belong to the CT skills. 
Table 6: The Critical Thinking Level

\begin{tabular}{l|c||c}
\hline \hline Critical Thinking & Median & IQR \\
\hline \hline Inference & 1.00 & 1.50 \\
\hline \hline Recognition of assumptions & 2.00 & 1.00 \\
\hline \hline Deduction & 2.00 & 1.00 \\
\hline \hline Interpretation & 2.00 & 2.00 \\
\hline \hline Evaluation of arguments & 2.00 & 1.00 \\
\hline \hline
\end{tabular}

Notes: The scales used for CT constructs are based on the WGCTA survey instrument where each construct has different scale including:

- Inference: $1=$ False; $2=$ True

- Recognition of assumptions: $1=\mathrm{No} ; 2=\mathrm{Yes}$

- Deduction: $1=$ No; $2=Y e s$

- Interpretation: $1=$ No; $2=Y e s$

- Evaluation of arguments: $1=$ Weak; $2=$ Strong

In general, the finding shows that CT level of postgraduate students is relatively low. It is reflected when the postgraduate students answered the second survey, which is on the relationship between CT and ISP. In fact, respondents who have low level of inference skill were generally not able to discriminate the relevance information which is important during information seeking process. On the other hand, respondents with high level of recognition of assumptions were able to recognize and evaluate information they gathered. Table 6 summarized the CT score of participants based on Median and IQR values. It shows in general, participants who were below average score in CT were having problem in inference $(\mathrm{Mdn}=1.00, I Q R=1.50)$ while participants with a high score in $C T$ were relatively good in recognition of assumptions $(M d n=2.00, I Q R=1.00)$.

\section{How postgraduate think critically in information seeking process?}

This research question was addressed through investigating the presence of CT skills in postgraduate's ISP. This section describes how CT skills were connected to each stage of the ISP. These relationships were based on the scales of the CT constructs. If the Median values are close to these data, ranges " 3 - usually", " 4 - often", and "always", the findings indicate that the participants has demonstrated to apply relevant CT skills in the ISP stage. In contrast, if the statements are indicated as $\mathrm{Mdn}=1(1=$ never $)$ it demonstrates that the CT skills were not applied in the ISP stages.

\section{a) Interpretation (CT) in initiation (ISP)}

Initiation is the first stage of ISP in which a person becomes aware of lack of knowledge, information and understanding to solve a complex problem or accomplish a search goal. During this stage, information seekers are uncertain about the aim of the search process, therefore, they would make effort to clarify and identify the problem.

Table 7 provides an overview on the Median and IQR values for all the CT skills in initiation stage. The findings indicate that the participants are demonstrated to employ the relevant CT skills in the ISP stage. This is indicated by Median $(\mathrm{Mdn})=3.00$ for the following statement:

i. Interpretation - statement 2: determine the existing information are related to the topic or not ( $M d n=3.00, I Q R=3.00)$.

ii. Recognition of assumptions - statement 4: distinguish relevant information from irrelevant information about the topic $(M d n=3.00, I Q R=2.00)$

iii. Inference - statement 5: (Mdn=3.00, IQR=3.00).

iv. Deduction - statement 6: recognize the unwarranted information about the topic (Mdn= 3.00, IQR=2.00). 
v. Deduction - statement 7: define terms and judge definitions by using appropriate criteria (Mdn=3.00, IQR=2.00).

vi. Evaluation of arguments - statement 8: determine the strength of arguments or information about the topic ( $M d n=3.00, I Q R=2.00$ )

vii. Evaluation of arguments - statement 9: decide to find the suitable answer (Mdn=3.00, IQR=3.00).

viii. Evaluation of arguments - statement 10: make a judgment about the answer and draw a conclusion (Mdn=3.00, IQR=3.00).

In contrast, the following statements were indicated as $\mathrm{Mdn}=1$ ( $1=$ never) that demonstrated the CT skills were not applied in the initiation stage:

i. Interpretation - statement 1: I clarify and interpret the meaning of the topic. (Mdn=1.00, IQR=2.00).

ii. Recognition of assumptions- statement 3: gather information ( $\mathrm{Mdn}=1.00$, IQR=2.00).

Table 7: Frequency, Median, and IQR Values for interpretation (CT) in initiation (ISP)

\begin{tabular}{|c|c|c|c|c|c|c|c|c|}
\hline \multirow{2}{*}{\multicolumn{2}{|c|}{$\begin{array}{l}\text { CT constructs } \\
\text { Interpretation }\end{array}$}} & \multicolumn{7}{|c|}{ Initiation (ISP stage) } \\
\hline & & \multirow{2}{*}{$\begin{array}{c}\text { Never } \\
60.0 \% \\
(27) \\
\end{array}$} & \multirow{2}{*}{$\begin{array}{c}\begin{array}{c}\text { Some- } \\
\text { times }\end{array} \\
0\end{array}$} & \multirow{2}{*}{$\begin{array}{c}\text { Usually } \\
35.0 \% \\
\text { (16) }\end{array}$} & \multirow{2}{*}{$\begin{array}{c}\text { Often } \\
4.4 \% \\
(2)\end{array}$} & \multirow{2}{*}{$\begin{array}{c}\text { Always } \\
0\end{array}$} & \multirow{2}{*}{$\begin{array}{c}\text { Median } \\
1.00\end{array}$} & \multirow{2}{*}{$\begin{array}{l}\text { IQR } \\
2.00\end{array}$} \\
\hline 1 & $\begin{array}{l}\text { I clarify and interpret the meaning } \\
\text { of the topic. }\end{array}$ & & & & & & & \\
\hline 2 & $\begin{array}{l}\text { I can determine the existing } \\
\text { information are related to the topic } \\
\text { or not }\end{array}$ & $\begin{array}{c}24.4 \% \\
(11)\end{array}$ & $\begin{array}{c}2.2 \% \\
(1)\end{array}$ & $\begin{array}{c}46.7 \% \\
(21)\end{array}$ & $\begin{array}{c}24.4 \% \\
(11)\end{array}$ & $\begin{array}{c}2.2 \% \\
(1)\end{array}$ & 3.00 & 3.00 \\
\hline \multicolumn{2}{|c|}{ Recognition of assumption } & Never & $\begin{array}{l}\text { Some- } \\
\text { times }\end{array}$ & Usually & Often & Always & Median & IQR \\
\hline 3 & I gather information & $\begin{array}{c}68.9 \% \\
(31) \\
\end{array}$ & $\begin{array}{c}2.2 \% \\
(1)\end{array}$ & $\begin{array}{c}26.7 \% \\
(12) \\
\end{array}$ & 0 & $\begin{array}{c}2.2 \% \\
(1)\end{array}$ & 1.00 & 2.00 \\
\hline 4 & $\begin{array}{l}\text { I distinguish relevant information } \\
\text { from irrelevant information about } \\
\text { the topic. }\end{array}$ & $\begin{array}{c}40.0 \% \\
(18)\end{array}$ & $\begin{array}{c}6.7 \% \\
(3)\end{array}$ & $\begin{array}{l}33.3 \% \\
(15)\end{array}$ & $\begin{array}{l}20.0 \% \\
(9)\end{array}$ & 0 & 3.00 & 2.00 \\
\hline \multicolumn{2}{|c|}{ Inference } & Never & $\begin{array}{l}\text { Some- } \\
\text { times }\end{array}$ & Usually & Often & Always & Median & IQR \\
\hline 5 & $\begin{array}{l}\text { I assess the information about the } \\
\text { topic and identify to reach a } \\
\text { reasonable conclusion. }\end{array}$ & $\begin{array}{l}35.6 \% \\
(16)\end{array}$ & $\begin{array}{c}11.1 \% \\
(5)\end{array}$ & $\begin{array}{c}28.9 \% \\
(13)\end{array}$ & $\begin{array}{c}22.2 \% \\
(10)\end{array}$ & $\begin{array}{c}2.2 \% \\
(1)\end{array}$ & 3.00 & 3.00 \\
\hline \multicolumn{2}{|c|}{ Deduction } & Never & $\begin{array}{l}\text { Some- } \\
\text { times } \\
\end{array}$ & Usually & Often & Always & Median & IQR \\
\hline 6 & $\begin{array}{l}\text { I recognize the unwarranted } \\
\text { information about the topic. }\end{array}$ & $\begin{array}{l}13.3 \% \\
(6)\end{array}$ & $\begin{array}{c}17.8 \% \\
(8)\end{array}$ & $\begin{array}{l}26.7 \% \\
(12)\end{array}$ & $\begin{array}{c}37.8 \% \\
(17)\end{array}$ & $\begin{array}{c}4.4 \% \\
(2)\end{array}$ & 3.00 & 2.00 \\
\hline 7 & $\begin{array}{l}\text { I define terms and judge definitions } \\
\text { by using appropriate criteria. }\end{array}$ & $\begin{array}{c}22.2 \% \\
(10)\end{array}$ & $\begin{array}{c}6.7 \% \\
(3) \\
\end{array}$ & $\begin{array}{c}35.6 \% \\
(16) \\
\end{array}$ & $\begin{array}{c}28.9 \% \\
(13)\end{array}$ & $\begin{array}{c}6.7 \% \\
(3)\end{array}$ & 3.00 & 2.00 \\
\hline \multicolumn{2}{|c|}{ Evaluation of arguments } & Never & $\begin{array}{l}\text { Some- } \\
\text { times } \\
\end{array}$ & Usually & Often & Always & Median & IQR \\
\hline 8 & $\begin{array}{l}\text { I determine the strength of } \\
\text { arguments or information about } \\
\text { the topic. }\end{array}$ & $\begin{array}{l}20.0 \% \\
(9)\end{array}$ & $\begin{array}{c}4.4 \% \\
(2)\end{array}$ & $\begin{array}{l}37.8 \% \\
(17)\end{array}$ & $\begin{array}{c}35.6 \% \\
(16)\end{array}$ & $\begin{array}{c}2.2 \% \\
(1)\end{array}$ & 3.00 & 2.00 \\
\hline 9 & I decide to find the suitable answer & $\begin{array}{c}35.6 \% \\
(16) \\
\end{array}$ & $\begin{array}{c}6.7 \% \\
(3) \\
\end{array}$ & $\begin{array}{c}33.3 \% \\
(15) \\
\end{array}$ & $\begin{array}{c}24.4 \% \\
(11) \\
\end{array}$ & 0 & 3.00 & 3.00 \\
\hline 10 & $\begin{array}{l}\text { I make a judgment about the } \\
\text { answer and draw a conclusion }\end{array}$ & $\begin{array}{c}24.4 \% \\
(11)\end{array}$ & $\begin{array}{c}11.1 \% \\
(5)\end{array}$ & $\begin{array}{c}33.3 \% \\
(15)\end{array}$ & $\begin{array}{c}24.4 \% \\
(11)\end{array}$ & $\begin{array}{c}6.7 \% \\
(3)\end{array}$ & 3.00 & 3.00 \\
\hline
\end{tabular}

Note: Scales for ISP includes: 1=Never; 2=Sometimes; 3= Usually; 4= Often; 5= Always 


\section{b) Recognition of assumption (CT) in Selection/exploration (ISP)}

Selection is the second stage of the ISP model that occurs after identifying the search task. In this stage, participants were optimist, although it might not be consistent. Since the participants are still exploring, they are uncertain, in doubt and confused because they still need to understand the problem to further investigate it. Table 8 shows the values of CT skills in selection/exploration stage of the ISP model.

Table 8: Frequency, Median, and IQR Values for recognition of assumptions (CT) in selection/exploration (ISP)

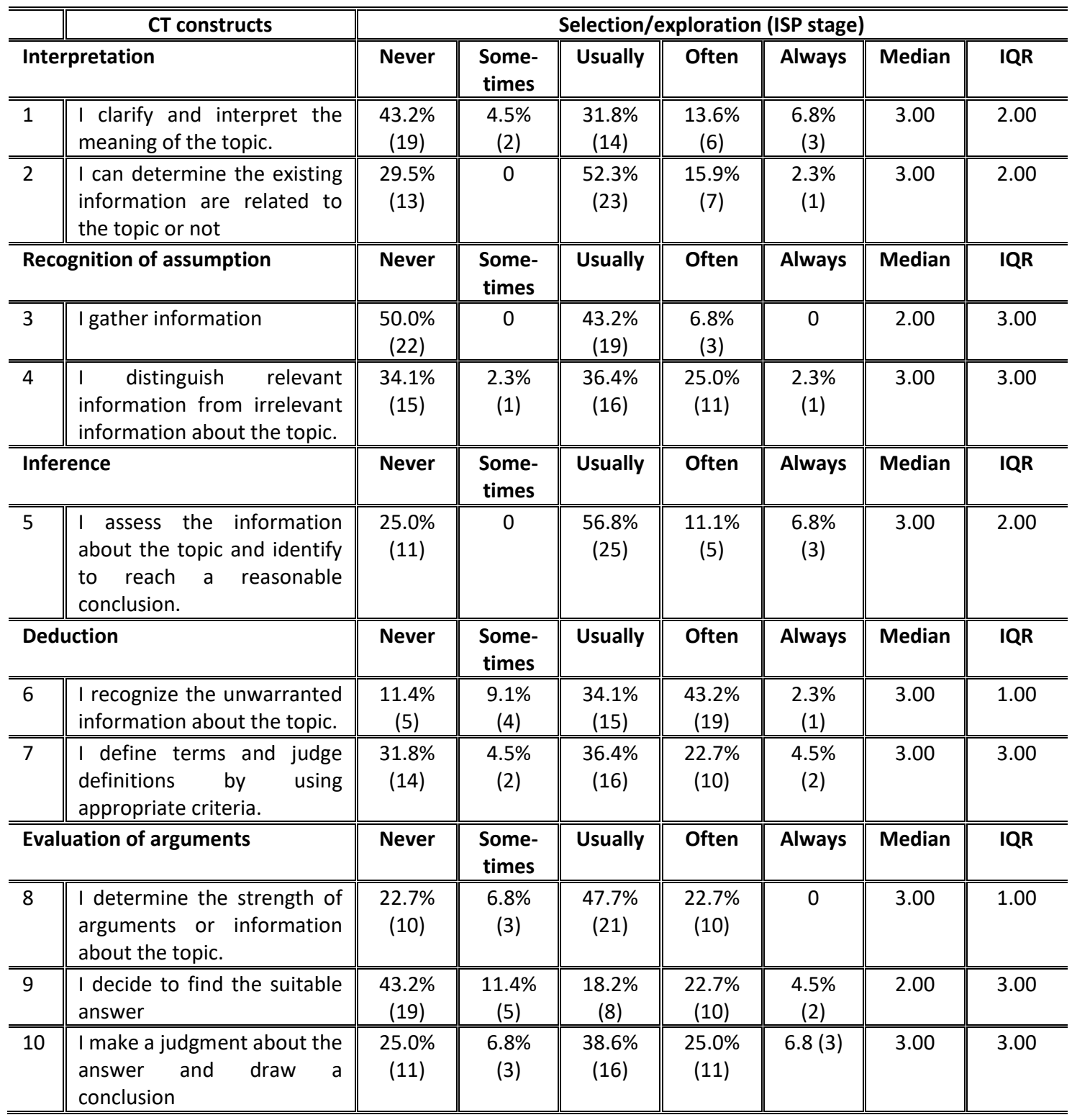

Note: Scales for ISP includes: 1=Never; 2=Sometimes; $3=$ Usually; $4=$ Often; $5=$ Always

The findings indicated that the participants have demonstrated to be able to apply the relevant CT skills in their ISP stage. This is indicated by $\mathrm{Mdn}=3.00$ for the following statements as shown in Table 8:

i. Interpretation - statement 1: clarify and interpret the meaning of the topic ( $M d n=3.00, I Q R=2.00)$

ii. Interpretation - statement 2: determine the existing information are related to the topic or not $(M d n=3.00, I Q R=2.00)$ 
iii. Recognition of assumptions- statement 4: distinguish relevant information from irrelevant information about the topic ( $M d n=3.00, I Q R=3.00$ )

iv. Inference - statement 5: assess the information about the topic and identify to reach a reasonable conclusion ( $M d n=3.00, I Q R=2.00$ )

v. Deduction - statement 6: recognize the unwarranted information about the topic (Mdn= 3.00, IQR=1.00)

vi. Deduction - statement 7: define terms and judge definitions by using appropriate criteria (Mdn=3.00, IQR=3.00)

vii. Evaluation of arguments - statement 8: determine the strength of arguments or information about the topic ( $M d n=3.00, I Q R=1.00$ )

viii. Evaluation of arguments - statement 10: make a judgment about the answer and draw a conclusion ( $M d n=3.00, I Q R=3.00)$

In contrast, the following statements were indicated as $M d n=2.00$ ( $2=$ sometimes) that demonstrated the CT skills were sometimes applied in the selection/exploration stages:

i. Recognition of assumptions - statement 3: gather information ( $M d n=2.00$, IQR=3.00)

ii. Evaluation of arguments - statement 9: decide to find the suitable answer $(\mathrm{Mdn}=2.00, \mathrm{IQR}=3.00)$

\section{c) Inference (CT) in formulation (ISP)}

In formulation stage, uncertainty level is diminished, and it is replaced by understanding. The participants were formed a focus from the information encountered in exploration. In Table 9 the Median and IQR values of CT skills related to the formulation stage were shown. The findings indicated that the participants have demonstrated to apply relevant CT skills in their ISP stage. This is indicated by $M d n=3.00$ for the following statement:

i. Interpretation - statement 1: clarify and interpret the meaning of the topic ( $M d n=3.00, I Q R=3.00$ )

ii. Interpretation - statement 2: can determine the existing information are related to the topic or not $(\mathrm{Mdn}=3.00, \mathrm{IQR}=2.00)$

iii. Recognition of assumptions - statement 3: gather information ( $M d n=3.00$, IQR=3.00)

iv. Recognition of assumptions - statement 4: distinguish relevant information from irrelevant information about the topic ( $M d n=3.00, I Q R=3.00$ )

v. Inference - statement 5: assess the information about the topic and identify to reach a reasonable conclusion $(\mathrm{Mdn}=3.00, \mathrm{IQR}=3.00)$

vi. Deduction - statement 6: recognize the unwarranted information about the topic (Mdn=3.00, IQR=2.00)

vii. Deduction - statement 7: define terms and judge definitions by using appropriate criteria (Mdn=3.00, IQR=3.00)

viii. Evaluation of arguments - statement 8: determine the strength of arguments or information about the topic ( $M d n=3.00, I Q R=2.00$ )

ix. Evaluation of arguments - statement 9: decide to find the suitable answer ( $M d n=3.00, I Q R=2.00)$

x. Evaluation of arguments- statement 10: make a judgment about the answer and draw a conclusion ( $M d n=3.00,1 Q R=2.00)$. 
Table 9: Frequency, Median, and IQR Values for inference (CT) in formulation (ISP)

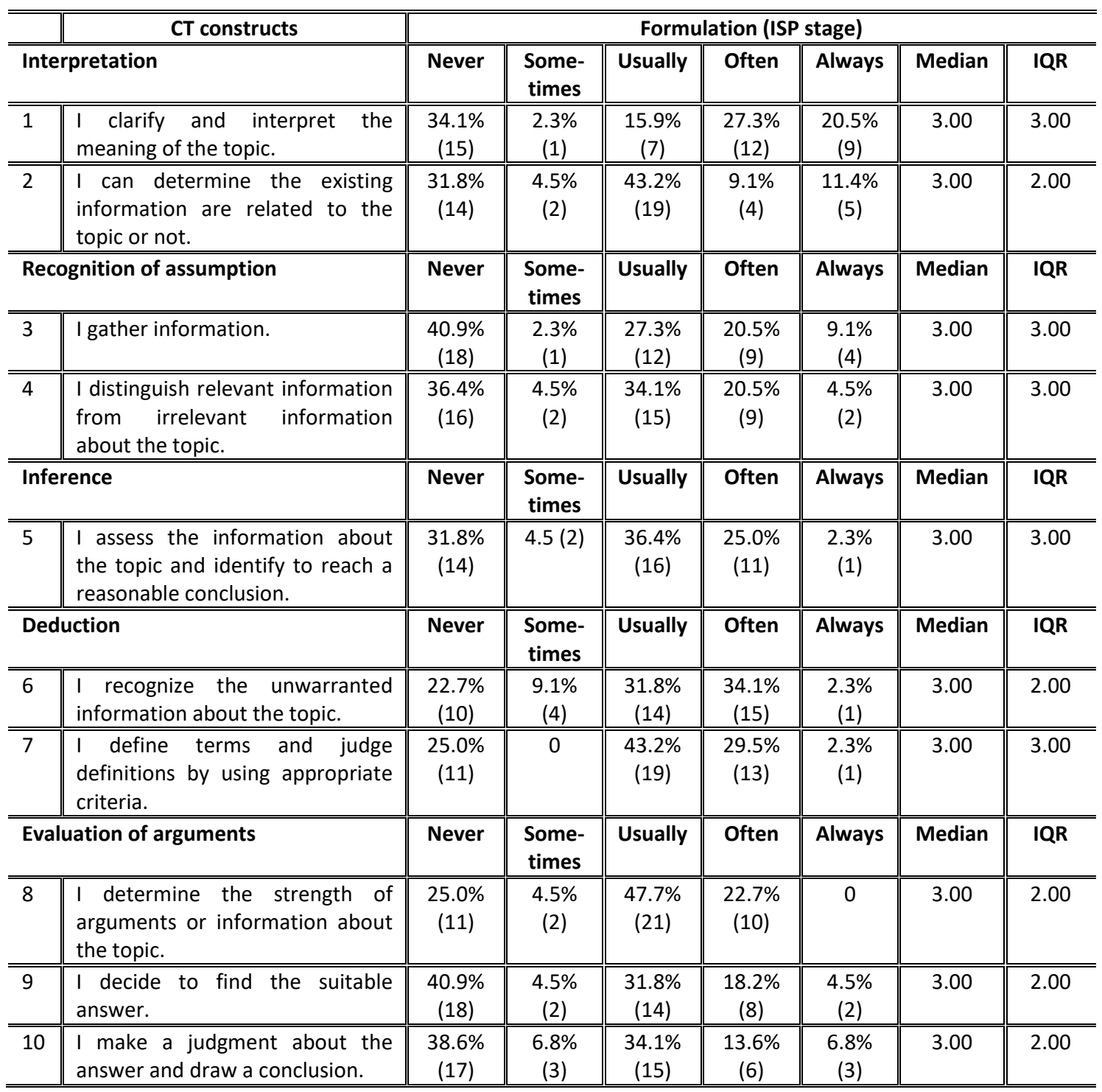

Note: Scales for ISP includes: 1=Never; 2=Sometimes; $3=$ Usually; 4= Often; 5= Always

\section{d) Deduction (CT) in information collection (ISP)}

Participants in the information collection stage of the ISP model had effective communication with the search system; therefore, they were able to collect information about the topic systematically. Table 10 explains how CT skills are related to the information collection stage of the ISP model. These relationships were based on the scales of the CT constructs. The findings indicated that the participants have demonstrated to apply relevant CT skills in their ISP stage. This is indicated by $\mathrm{Mdn}=3.00$ for the following statement:

i. Interpretation - statement 1: clarify and interpret the meaning of the topic (Mdn=3.00, IQR=3.00)

ii. Interpretation - statement 2: can determine the existing information are related to the topic or not (Mdn=3.00, IQR=3.00)

iii. Recognition of assumptions - statement 3: gather information (Mdn=3.00, IQR=1.00)

iv. Recognition of assumptions - statement 4: distinguish relevant information from irrelevant information about the topic $(M d n=3.00, I Q R=2.00)$ 
v. Inference - statement 5: assess the information about the topic and identify to reach a reasonable conclusion ( $\mathrm{Mdn}=3.00, \mathrm{IQR}=3.00$ )

vi. Deduction - statement 6: recognize the unwarranted information about the topic ( $M d n=3.00, I Q R=2.00)$

vii. Deduction - statement 7: define terms and judge definitions by using appropriate criteria (Mdn=3.00, IQR=2.00)

viii. Evaluation of arguments - statement 8: determine the strength of arguments or information about the topic ( $M d n=3.00, I Q R=3.00$ )

ix. Evaluation of arguments - statement 9: decide to find the suitable answer ( $M d n=3.00, I Q R=2.00)$

$\mathrm{x}$. Evaluation of arguments- statement 10: make a judgment about the answer and draw a conclusion $(\mathrm{Mdn}=3.00, \mathrm{IQR}=2.00)$.

Table 1 Frequency, Median, and IQR Values for deduction (CT) in information collection (ISP)

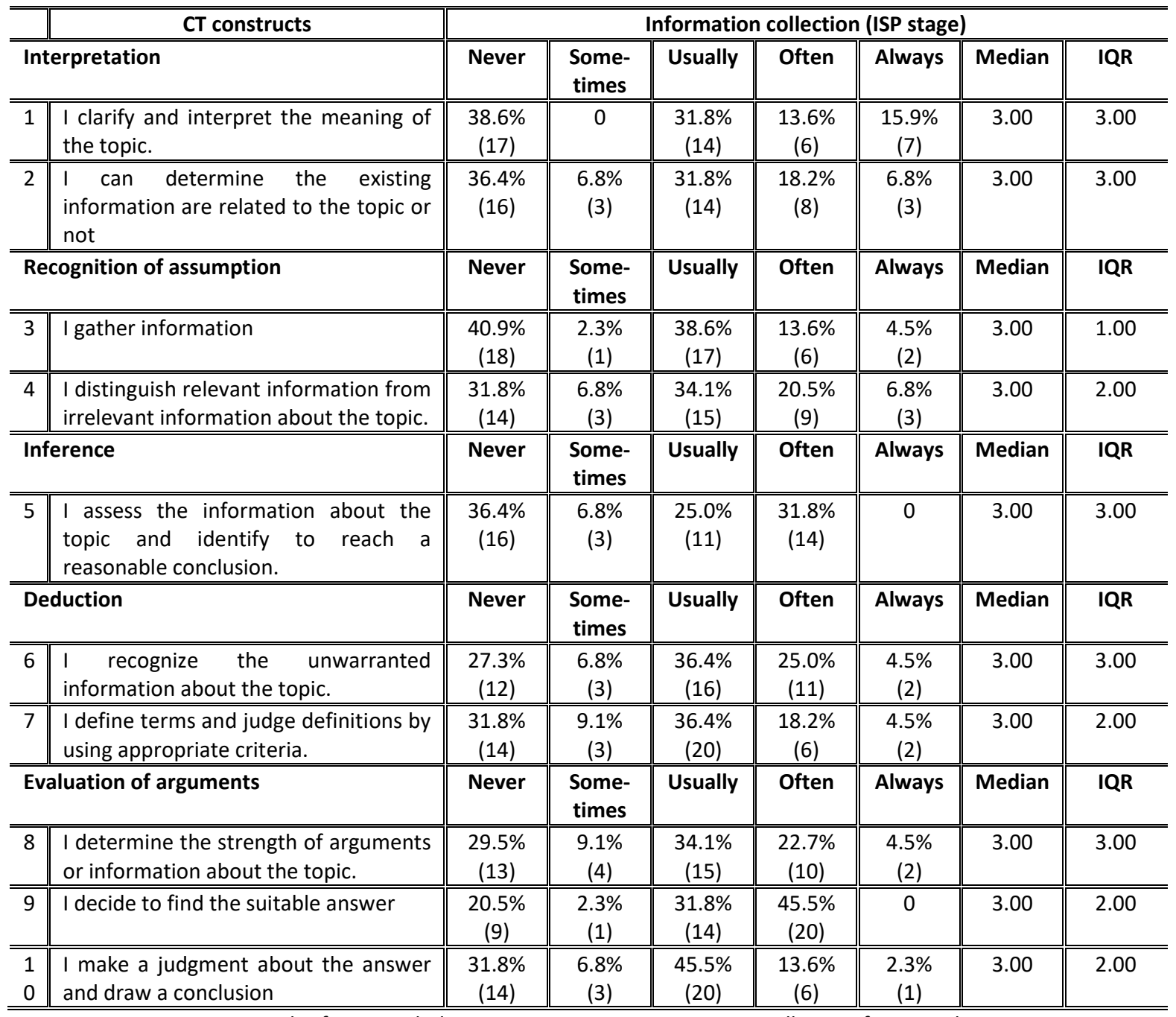




\section{e) Evaluation of arguments (CT) in presentation (ISP)}

In the final stage of the ISP model, information seekers completed their search activities and achieve their needs. Table 11 demonstrated how CT skills are related to the presentation stage of the ISP model. The findings indicated that the participants have demonstrated to apply relevant CT skills in their ISP stage. This is indicated by $\mathrm{Mdn}=3.00$ for the following statement:

i. Interpretation - statement 1: clarify and interpret the meaning of the topic ( $M d n=3.00, I Q R=4.00)$

ii. Interpretation - statement 2: can determine the existing information are related to the topic or not (Mdn=3.00, IQR=3.00)

iii. Recognition of assumptions - statement 3: gather information ( $M d n=3.00,1 Q R=3.00$ )

iv. Recognition of assumptions - statement 4: distinguish relevant information from irrelevant information about the topic ( $M d n=3.00, I Q R=3.00)$

v. Inference - statement 5: assess the information about the topic and identify to reach a reasonable conclusion ( $\mathrm{Mdn}=3.00, \mathrm{IQR}=3.00$ )

vi. Deduction - statement 6: recognize the unwarranted information about the topic (Mdn=3.00, IQR=2.00)

In contrast, the following statements were indicated as $M d n=2$ (2=Sometimes) that demonstrated the $\mathrm{CT}$ skills were sometimes applied in the selection/exploration stages:

i. Deduction - statement 7: define terms and judge definitions by using appropriate criteria (Mdn=2.00, IQR=3.00)

ii. Evaluation of arguments- statement 8: determine the strength of arguments or information about the topic ( $M d n=2.00, I Q R=3.00)$

In light of the median values, if $\mathrm{Mdn}=1$ ( $1=$ Never), the following statements were indicated that CT skills were not employed in the presentation stage:

i. Evaluation of arguments- statement 9: decide to find the suitable answer ( $M d n=1.00$, IQR=2.00)

ii. Evaluation of arguments- statement 10: make a judgment about the answer and draw a conclusion $(\mathrm{Mdn}=1.00, \mathrm{IQR}=2.00)$

Figure 2 illustrates how CT skills are related to each stages of the ISP model. Figure 2 depicts relationship between CT and ISP based on the analysis of the second survey. According to the median and IQR values, the relationships between CT skills in each stage of the ISP model are shown. For example, in initiation stage, participants demonstrated to apply "inference", "deduction", and "evaluation of arguments" skills more than "interpretation" skill and "recognition of assumptions". In selection/exploration stage of the ISP model, "interpretation", "deduction", and "inference" skills were more applicable than "recognition of assumptions" and evaluation of arguments" skills. During formulation and information collection stage of the ISP model, participants exhibited the use of all the CT skills including: "interpretation", "and recognition of assumptions", "inference", "deduction and evaluation of arguments". At the end of the seeking process, participants presented their outcome of the search activities. As a result, some of them mentioned that they may return to the previous stages to evaluate what they did earlier. It was revealed that "interpretation", "recognition of assumptions", and "inference" were more useful skills rather than "deduction" and "evaluation of arguments" skills. 
Table 11: Frequency, Median, and IQR Values for evaluation of arguments (CT) in presentation (ISP)

\begin{tabular}{|c|c|c|c|c|c|c|c|c|}
\hline \multicolumn{2}{|c|}{\begin{tabular}{r||r} 
& CT constructs \\
\end{tabular}} & \multicolumn{7}{|c|}{ Presentation (ISP stage) } \\
\hline \multicolumn{2}{|c|}{ Interpretation } & Never & Some- & Usually & Often & Always & Median & IQR \\
\hline 1 & $\begin{array}{l}\text { I clarify and interpret the } \\
\text { meaning of the topic. }\end{array}$ & $\begin{array}{c}38.6 \% \\
(17)\end{array}$ & $\begin{array}{c}2.3 \% \\
(1)\end{array}$ & $\begin{array}{c}18.2 \% \\
(8)\end{array}$ & $\begin{array}{c}11.4 \% \\
(5)\end{array}$ & $\begin{array}{c}29.5 \% \\
(13)\end{array}$ & 3.00 & 4.00 \\
\hline 2 & $\begin{array}{l}\text { I can determine the existing } \\
\text { information are related to the } \\
\text { topic or not }\end{array}$ & $\begin{array}{c}25.0 \% \\
(11)\end{array}$ & $\begin{array}{c}9.1 \% \\
(4)\end{array}$ & $\begin{array}{c}27.3 \% \\
(12)\end{array}$ & $\begin{array}{c}22.7 \% \\
(10)\end{array}$ & $\begin{array}{c}15.9 \% \\
(7)\end{array}$ & 3.00 & 3.00 \\
\hline \multicolumn{2}{|c|}{ Recognition of assumption } & Never & $\begin{array}{c}\text { Some- } \\
\text { times }\end{array}$ & Usually & Often & Always & Median & IQR \\
\hline 3 & I gather information & $\begin{array}{c}31.8 \% \\
(14)\end{array}$ & $\begin{array}{c}2.3 \% \\
(1)\end{array}$ & $\begin{array}{c}27.3 \% \\
(12) \\
\end{array}$ & $\begin{array}{c}18.2 \% \\
(8)\end{array}$ & $\begin{array}{l}20.5 \% \\
(9)\end{array}$ & 3.00 & 3.00 \\
\hline 4 & $\begin{array}{l}\text { I distinguish relevant } \\
\text { information from irrelevant } \\
\text { information about the topic. }\end{array}$ & $\begin{array}{c}27.3 \% \\
(12)\end{array}$ & $\begin{array}{c}9.1 \% \\
(4)\end{array}$ & $\begin{array}{c}27.3 \% \\
(12)\end{array}$ & $\begin{array}{c}25.0 \% \\
(11)\end{array}$ & $\begin{array}{c}11.4 \% \\
(5)\end{array}$ & 3.00 & 3.00 \\
\hline \multicolumn{2}{|c|}{ Inference } & Never & $\begin{array}{l}\text { Some- } \\
\text { times }\end{array}$ & Usually & Often & Always & Median & IQR \\
\hline 5 & $\begin{array}{l}\text { I assess the information about } \\
\text { the topic and identify to reach a } \\
\text { reasonable conclusion. }\end{array}$ & $\begin{array}{c}38.6 \% \\
(17)\end{array}$ & $\begin{array}{l}9.1 \% \\
(4)\end{array}$ & $\begin{array}{c}22.7 \% \\
(10)\end{array}$ & $\begin{array}{l}20.5 \% \\
(9)\end{array}$ & $\begin{array}{l}9.1 \% \\
(4)\end{array}$ & 3.00 & 3.00 \\
\hline \multicolumn{2}{|c|}{ Deduction } & Never & $\begin{array}{l}\text { Some- } \\
\text { times }\end{array}$ & Usually & Often & Always & Median & IQR \\
\hline 6 & $\begin{array}{l}\text { I recognize the unwarranted } \\
\text { information about the topic. }\end{array}$ & $\begin{array}{c}29.5 \% \\
(13)\end{array}$ & $\begin{array}{c}15.9 \% \\
(7)\end{array}$ & $\begin{array}{l}20.5 \% \\
(9)\end{array}$ & $\begin{array}{c}25.0 \% \\
(11)\end{array}$ & $\begin{array}{l}9.1 \% \\
(4)\end{array}$ & 3.00 & 3.00 \\
\hline 7 & $\begin{array}{l}\text { I define terms and judge } \\
\text { definitions by using appropriate } \\
\text { criteria. }\end{array}$ & $\begin{array}{c}40.9 \% \\
(18)\end{array}$ & $\begin{array}{c}11.4 \% \\
(5)\end{array}$ & $\begin{array}{c}18.2 \% \\
(8)\end{array}$ & $\begin{array}{c}25.0 \% \\
(10)\end{array}$ & $\begin{array}{c}4.5 \% \\
92)\end{array}$ & 2.00 & 3.00 \\
\hline \multicolumn{2}{|c|}{ Evaluation of arguments } & Never & $\begin{array}{l}\text { Some- } \\
\text { times }\end{array}$ & Usually & Often & Always & Median & IQR \\
\hline 8 & $\begin{array}{l}\text { I determine the strength of } \\
\text { arguments or information about } \\
\text { the topic. }\end{array}$ & $\begin{array}{c}45.5 \% \\
(20)\end{array}$ & $\begin{array}{l}6.8 \% \\
(3)\end{array}$ & $\begin{array}{c}18.2 \% \\
(8)\end{array}$ & $\begin{array}{c}25.0 \% \\
(11)\end{array}$ & $\begin{array}{l}4.5 \% \\
(2)\end{array}$ & 2.00 & 3.00 \\
\hline 9 & $\begin{array}{l}\text { I decide to find the suitable } \\
\text { answer }\end{array}$ & $\begin{array}{c}48.9 \% \\
(21)\end{array}$ & $\begin{array}{c}6.8 \% \\
(3)\end{array}$ & $\begin{array}{c}27.3 \% \\
(12) \\
\end{array}$ & $\begin{array}{c}13.6 \% \\
(6)\end{array}$ & $\begin{array}{c}2.3 \% \\
(1)\end{array}$ & 1.00 & 2.00 \\
\hline 10 & $\begin{array}{l}\text { I make a judgment about the } \\
\text { answer and draw a conclusion }\end{array}$ & $\begin{array}{c}61.4 \% \\
(27)\end{array}$ & $\begin{array}{c}6.8 \% \\
(3)\end{array}$ & $\begin{array}{c}22.7 \% \\
(10)\end{array}$ & $\begin{array}{c}9.1 \% \\
(4)\end{array}$ & 0 & 1.00 & 2.00 \\
\hline
\end{tabular}

Note: Scales for ISP includes: 1=Never; 2=Sometimes; $3=$ Usually; $4=$ Often; $5=$ Always

\section{DISCUSSION}

This study attempted to examine the level of CT by using the WGCTA-UK edition. The finding reported about 71 percent of postgraduate students scored below and average. At about 29 percent of them obtained high score in CT. It can be seen that postgraduate students suffer from lack of CT and it influences their behavior while they seek information. For example, the respondents who scored low and average in CT skill, demonstrated lack of skill in the inference. On the other hand, the respondents who scored higher in CT skill, demonstrated relatively good in "recognition of assumption". 


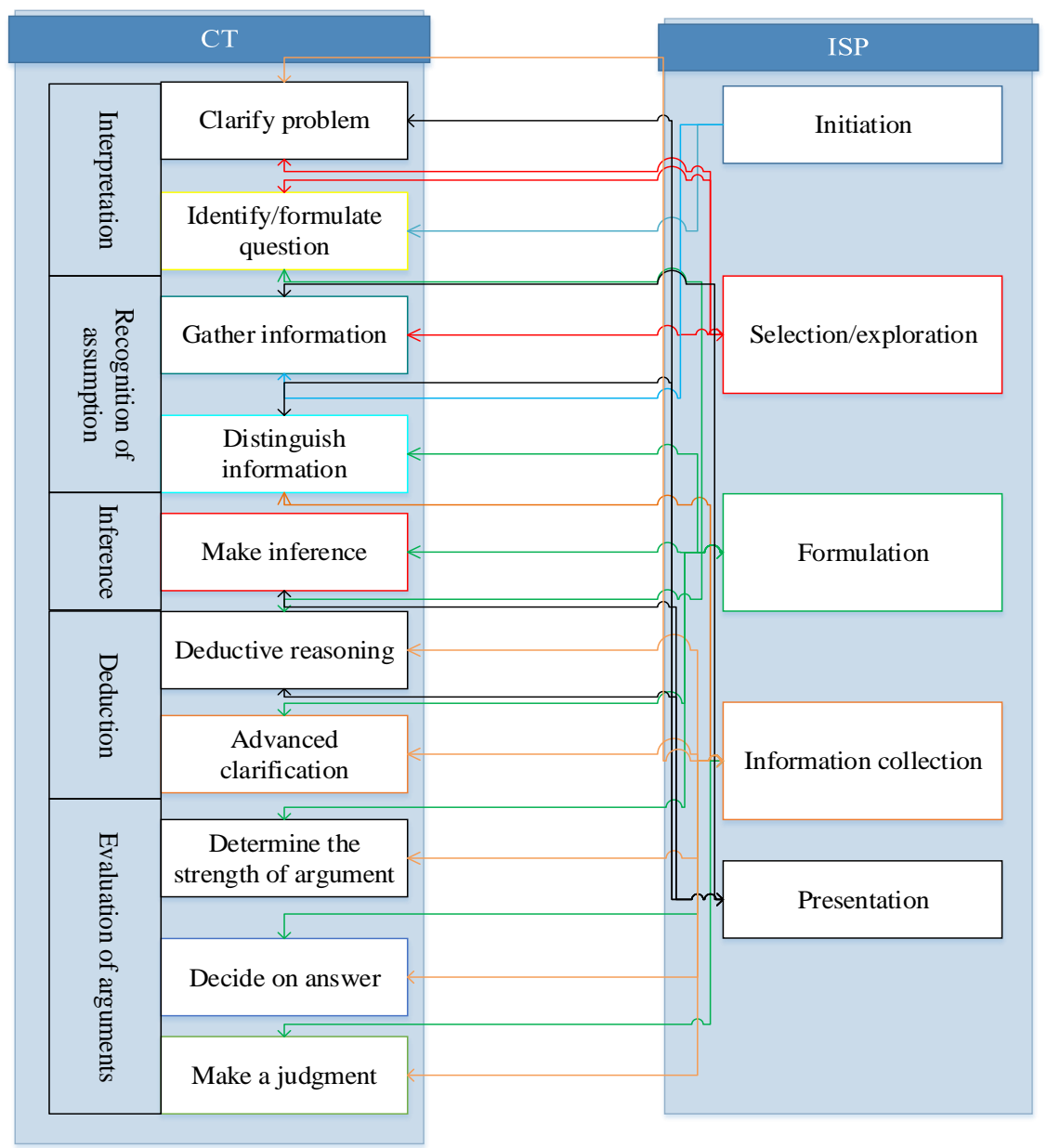

Figure 2: The Relationship between CT and ISP

In answering the second research question whether the postgraduate students use CT skills while seeking for information, the association between both CT skills and the ISP were investigated through a survey instrument. In the initiation stage of ISP, the CT constructs were employed by the respondents particularly for "inference, deduction, and evaluation of arguments" as indicated by $M d n=3$. However they were partly employed "interpretation and recognition of assumptions" by $M d n=1$. In the selection/exploration stage of the ISP model, the CT constructs which were fully employed by the respondents included "interpretation, deduction, and inference" as shown by $M d n=3$. "Evaluation of arguments and recognition of assumptions" were partially applied by the respondents in selection/exploration stages as shown on $\mathrm{Mdn}=2$. In "formulation" stage of the ISP model, it can be seen that "interpretation, recognition of assumptions, inference, deduction, and evaluation of arguments" were fully employed by the respondents as demonstrated by $M d n=3$. In information collection, due to the nature of this stage which required users to make use all ISP, the respondents indicated that all CT skills were fully utilized. Therefore, "interpretation, recognition of assumptions, inference, deduction, and evaluation of arguments" were the most employed CT skills in information collection stage as shown by $M d n=3$. In the final stage of the ISP model, "interpretation, recognition of assumptions, and inference" were fully utilized by the respondents as shown in $\mathrm{Mdn}=3.00$, while, "evaluation of arguments and deduction" were hardly employed by the respondents as shown by $M d n=1$ ( $1=$ Never) and $M d n=2$ ( 2 =Sometimes). 


\section{CONCLUSION}

Being equipped with CT skills is important because these skills play a vital role for students. CT skills allow students to question assumptions, analyze arguments, and evaluate the quality of information which they encounter in their fields (Bensley and Spero 2014). In addition, it creates an opportunity for students to be well-equipped with higher-order thinking skills and qualified as competent citizen. One of the main contributions of this study is to examine the level of CT skill among postgraduate students. The results revealed that only 29 percent of the postgraduate students score acceptable points from WGCTAUK edition survey. Therefore, it indicated the level of CT among these participants were low and required an improvement. The other contribution is to investigate the relationship between CT and ISP. Indeed, this contribution is based on the theory that claimed critical thinkers are able to seek better and more accurate information (Ennis 1989). However, most industries had complained about lack of CT among workforces as well as allocating particular budget with the aim of developing CT among higher learning institutes (Shakir 2009, Hambur, Rowe, and Luc 2002, Walsh and Seldomridge 2006). As a result, it can validate the lack of $C T$ among postgraduate students. On the other hand, some researchers categorized information seeking as an important component of CT dispositions (Bailin et al. 1999, Ennis 1985, Paul 1992, Facione and Facione 2007, Facione, Facione, and Giancarlo 2000), which indicated the existing relationship between CT skills and ISP.

In connection with library user education, (Kuhlthau 2002) has developed a further step in assessing the ISP, which is the evaluation stage. At this stage, identification of what cause difficulty, and determination of what could have been done differently to improve the process of learning as well as the final product is carried out. It is important that information literacy programs should be able to educate users to use time effectively when searching for information, use suitable sources and consult librarians whenever they need. As abundant of information is available on the Internet, it can be difficult for users to have an overview of the most reasonable way to seek for information. Consequently, most of academic libraries are offering information literacy programs particularly in teaching the patrons to properly use the available information systems. In addition, some of the libraries were reported to integrate students' project work into the information literacy curriculum (Fainburg 2009).

This paper reported preliminary findings of a larger research work, therefore generalization of the result should be treated with caution. Future research could be conducted to investigate strategies that could be employed to instill and develop CT skill among students. In addition, further study could be done to investigate other CT skills such as analysis, self-regulation, and explanation to exhibit a clear usage of CT skills and dispositions in decision making process.

\section{ACKNOWLEDGEMENT}

This work has been supported by University of Malaya, Malaysia, under Grant FL005-12. 


\section{REFERENCES}

Abrami, P. C., Bernard, R. M., Borokhovski, E., Wade, A., Surkes, M. A., Tamim, R., and Zhang, D. 2008. Instructional interventions affecting critical thinking skills and dispositions: A stage 1 meta-analysis. Review of Educational Research, Vol. 78, no. 4 1102-1134.

Al Qadire, M. 2014. Jordanian cancer patients' information needs and information-seeking behaviour: A descriptive study. European Journal of Oncology Nursing, Vol. 18, no. 1: 46-51. Available at doi: http://dx.doi.org/10.1016/j.ejon.2013.09.007.

Aloqaili, A. S. 2012. The relationship between reading comprehension and critical thinking: A theoretical study. Journal of King Saud University - Languages and Translation, Vol. 24, no. 1: 35-41. doi: http://dx.doi.org/10.1016/j.jksult.2011.01.001.

Bailin, S., Case, R., Coombs, J. R., and Daniels, L. B. 1999. Conceptualizing critical thinking. Journal of Curriculum Studies, Vol. 31, no. 3: 285-302.

Barrett, J. E., Sarama, J., Clements, D. H., Cullen, C., McCool, J., Witkowski-Rumsey, C., and Klanderman, D. 2012. Evaluating and Improving a Learning Trajectory for Linear Measurement in Elementary Grades 2 and 3: A Longitudinal Study. Mathematical Thinking and Learning, Vol.14, no. 1: 28-54. doi: 10.1080/10986065.2012.625075.

Behar-Horenstein, L. S., and Niu, L. 2011. Teaching critical thinking skills in higher education: A review of the literature. Journal of College Teaching \& Learning (TLC), Vol. 8, no. 2: 25-41

Bensley, D. A., and Spero, R. A. 2014. Improving critical thinking skills and metacognitive monitoring through direct infusion. Thinking Skills and Creativity, Vol. 12: 55-68. doi: http://dx.doi.org/10.1016/j.tsc.2014.02.001.

Branch, J. L. 2003. Nontraditional undergraduates at home, work, and school: an examination of information-seeking behaviors and the impact of information literacy instruction. Research Strategies, Vol. 19, no. 1: 3-15. doi: http://dx.doi.org/10.1016/j.resstr.2003.09.002.

Byron, S. M., and Young, J. I. 2000. Information seeking in a virtual learning environment. Research Strategies, Vol. 17, no. 4: 257-267. doi: http://dx.doi.org/10.1016/S07343310(01)00055-6.

Chowdhury, S., Gibb, F., and Landoni, M. 2011. Uncertainty in information seeking and retrieval: A study in an academic environment. Information Processing \& Management, Vol. 47, no. 2:157-175. doi: http://dx.doi.org/10.1016/j.ipm.2010.09.006.

Colucciello, M. L. 1999. Relationships between critical thinking dispositions and learning styles. Journal of Professional Nursing, Vol. 15, no. 5: 294-301. doi: http://dx.doi.org/10.1016/S8755-7223(99)80055-6.

De Wever, B., Schellens, T., Valcke, M., and Van Keer, H. 2006. Content analysis schemes to analyze transcripts of online asynchronous discussion groups: A review. Computers \& Education, Vol. 46, no. 1: 6-28. doi: http://dx.doi.org/10.1016/j.compedu.2005.04.005.

Dwyer, C. P., Hogan, M. J., and Stewart, I. 2014. An integrated critical thinking framework for the 21st century. Thinking Skills and Creativity, Vol. 12: 43-52. doi: http://dx.doi.org/10.1016/j.tsc.2013.12.004.

Ellis, D., and Haugan, M. 1997. Modelling the information seeking patterns of engineers and research scientists in an industrial environment. Journal of documentation, Vol. 53, no. 4: 384-403.

Ennis, C. D. 1991. Discrete thinking skills in two teachers' physical education classes. The Elementary School Journal, Vol. 91, no. 5: 473-487. doi: 10.2307/1001888. 
Ennis, R. H. 1985. A logical basis for measuring critical thinking skills. Educational leadership, Vol. 43, no. 2: 44-48.

Ennis, R. H. 1987. A taxonomy of critical thinking dispositions and abilities. In Teaching Thinking Skills: Theory and Practice, edited by J. B. Baron R. J. Sternberg, 9-26. New York: W H Freeman/Times Books/ Henry Holt \& Co.

Ennis, R. H. 1989. Critical thinking and subject specificity: Clarification and needed research. Educational researcher, Vol. 18, no. 3: 4-10.

Erfanmanesh, M., Abrizah, A., and Karim, N. H. A. 2014. The prevalence and correlates of information seeking anxiety in postgraduate students. Malaysian Journal of Library \& Information Science, Vol. 19, no. 2: 69-82.

Facione, N. C., and Facione, P. A. 2007. Perceived prejudice in healthcare and women's health protective behavior. Nursing Research, Vol. 56, no. 3: 175-184.

Facione, P. A. 1990. Critical Thinking: a statement of expert consensus for purposes of educational assessment and instruction. Research Findings and Recommendations. California Academic Press, http://files.eric.ed.gov/fulltext/ED315423.pdf.

Facione, P. A., Facione, N. C., and Giancarlo, C. A. F. 2000. The disposition toward critical thinking: Its character, measurement, and relationship to critical thinking skill. Informal logic, Vol. 20, no. 1: 61-84.

Fainburg, L. I. 2009. Information seeking and learning: a comparison of Kuhlthau's information seeking model and John Dewey's problem solving model. New Library World, Vol. 110, no.9/10:457-466.

Hambur, S., Rowe, K., and Luc, L. 2002. Graduate skills assessment: stage one validity. Canbera: Australian Council for Educational Research.

Hassan, K., and Madhum, G. 2007. Validating the Watson Glaser critical thinking appraisal. Higher Education, Vol. 54, no. 3: 361-383. doi: 10.1007/s10734-006-9002-z.

Hyldegård, J. 2006. Using diaries in group based information behavior research: a methodological study. In Proceedings of the 1st International Conference on Information Interaction in Context, Copenhegen: ACM, 18-20 October.

Jamali, H. R., and Nicholas, D. 2010. Interdisciplinarity and the information-seeking behavior of scientists. Information Processing \& Management, Vol. 46, no. 2: 233243. doi: http://dx.doi.org/10.1016/j.ipm.2009.12.010.

Kek, M. Y. C. A., and Huijser, H. 2011. The power of problem-based learning in developing critical thinking skills: preparing students for tomorrow's digital futures in today's classrooms. Higher Education Research \& Development, Vol. 30, no. 3: 329-341.

Kuhlthau, C. C. 1991. Inside the search process: Information seeking from the user's perspective. JASIS, Vol. 42, no. 5: 361-371.

Kuhlthau, C. C. 2002. Teaching the library research process. 2nd ed. Boston, Maryland: The Scarecrow Press.

Kuhlthau, C. C. 2004. Seeking meaning: A process approach to library and information services. 2nd ed. Westport, CT: Libraries Unlimited Incorporation.

Lai, E. R. 2011. Critical thinking: A literature review. UK: Pearson research report. Available at:http://images. pearsonassessments.com/images/tmrs/CriticalThinkingReviewFINAL. pdf.

Ledward, B. C., and Hirata, D. 2011. An Overview of 21st Century Skills. EVALUATION.

Lipman, M. 1988. Critical Thinking--What Can It Be? Educational Leadership, Vol. 46, no. 1: 38-43.

Liyana, S., and Noorhidawati, A. 2014. How graduate students seek for information: Convenience or guaranteed result?. Malaysian Journal of Library \& Information Science, Vol. 19, no. 2: 1-15. 
Lun, V. M.-C., Fischer, R., and Ward, C. 2010. Exploring cultural differences in critical thinking: Is it about my thinking style or the language I speak? Learning and Individual Differences, Vol. 20, no. 6: 604-616. doi: http://dx.doi.org/10.1016/j.lindif.2010.07.001.

Madden, R. 2014. Information behaviour of humanities PhDs on an information literacy course. Reference Services Review, Vol. 42, no. 1: 90-107. doi: 10.1108/RSR-07-20130034.

Malliari, A., Korobili, S., and Zapounidou, S. 2011. Exploring the information seeking behavior of Greek graduate students: A case study set in the University of Macedonia. The International Information \& Library Review, Vol. 43, no. 2: 79-91. doi: http://dx.doi.org/10.1016/j.iilr.2011.04.006.

Marchionini, G. 1997. Information seeking in electronic environments. Cambridge: Cambridge University Press.

Naber, J., and Wyatt, T. H. 2014. The effect of reflective writing interventions on the critical thinking skills and dispositions of baccalaureate nursing students. Nurse Education Today, Vol. 34, no. 1: 67-72. doi: http://dx.doi.org/10.1016/j.nedt.2013.04.002.

Paul, R. 1992. Critical thinking: What, why, and how. New Directions for Community Colleges, Vol. 1992, no. 77: 3-24. doi: 10.1002/cc.36819927703.

Popham, W. J. 2000. Modern educational measurement: Practical guidelines for educational leaders. California: Allyn \& Bacon.

Poteri, E. 2007. Collaborative information behaviour: a case study of two research groups. $\mathrm{PhD}$, Information Studies, University of Helsinki.

Shah, C., and González-Ibáñez, R. 2010. Exploring information seeking processes in collaborative search tasks. Proceedings of the American Society for Information Science and Technology, Vol. 47, no. 1:1-7.

Shakir, R. 2009. Soft skills at the Malaysian institutes of higher learning. Asia Pacific Education Review, Vol. 10, no. 3: 309-315. doi: 10.1007/s12564-009-9038-8.

Silvester, J., and Dykes, C. 2007. Selecting political candidates: A longitudinal study of assessment centre performance and political success in the 2005 UK General Election. Journal of Occupational and Organizational Psychology, Vol. 80, no. 1: 11-25.

Spezi, V. 2016. Is information-seeking behaviour of doctoral students changing?: a review of the literature (2010-2015). New Review of Academic Librarianship, Vol. 22, no. 1: 78-106.

ten Dam, G., and Volman, M. 2004. Critical thinking as a citizenship competence: teaching strategies. Learning and Instruction, Vol. 14, no. 4: 359-379. doi: http://dx.doi.org/10.1016/j.learninstruc.2004.01.005.

Tsui, L. 2002. Fostering critical thinking through effective pedagogy: Evidence from four institutional case studies. The Journal of Higher Education, Vol. 73, no. 6: 740-763.

Wahoush, O., and Banfield, L. 2014. Information literacy during entry to practice: Information-seeking behaviors in student nurses and recent nurse graduates. Nurse Education Toda, Vol. 34, no. 2: 208-213. doi: http://dx.doi.org/10.1016/ j.nedt.2013.04.009.

Walsh, C. M., and Seldomridge, L. A. 2006. Measuring Critical Thinking: One Step Forward, One Step Back. Nurse Educator, Vol. 31, no. 4: 159-162.

Watson, G., and Glaser, E. 2002. Watson-Glaser Critical Thinking Appraisal, UK Edition: Practice Test. London: Psychological Corporation.

Webb, M. E. 1994. Beginning computer-based modelling in primary schools. Computers \& Education, Vol. 22, no. 1-2: 129-144. doi: http://dx.doi.org/10.1016/03601315(94)90081-7. 
Weiler, A. 2005. Information-seeking behavior in Generation $Y$ students: Motivation, critical thinking, and learning theory. The Journal of Academic Librarianship, Vol. 31, no. $1: 46-53$.

Williamson, K., and Asla, T. 2009. Information behavior of people in the fourth age: Implications for the conceptualization of information literacy. Library \& Information Science Research, Vol. 31, no. 2: 76-83. doi: http://dx.doi.org/10.1016/j.lisr.2009.01.002.

Wilson, T. D. 1997. Information behaviour: An interdisciplinary perspective. Information Processing \& Management, Vol. 33, no. 4: 551-572. doi: http://dx.doi.org/10.1016/S0306-4573(97)00028-9.

Wilson, T. D. 1999. Models in information behaviour research. Journal of documentation Vol. 55, no. 3: 249-270.

Wilson, T. D., Ford, N. J., Ellis, D., Foster, A. E., and Spink, A. 2002. Information seeking and mediated searching: Part 2. Uncertainty and its correlates. Journal of the American society for Information Science and Technology, Vol. 53, no. 9: 704-715.

Xie, I. 2009. Dimensions of tasks: influences on information-seeking and retrieving process. Journal of Documentation, Vol. 65, no. 3: 339-366.

Yiqi, L. 2012. Enhancing Critical Thinking: Analyzing Classroom Interactions in the Age of Web 2.0. Procedia - Social and Behavioral Science, Vol. 5: 386-391. doi: http://dx.doi.org/10.1016/j.sbspro.2012.08.177.

Zhou, M. 2014. Gender difference in web search perceptions and behavior: Does it vary by task performance? Computers \& Education, Vol. 78: 174-184. doi: http://dx.doi.org/10.1016/j.compedu.2014.06.005. 